Original Article

\title{
Effects of diaphragm breathing exercise and feedback breathing exercise on pulmonary function in healthy adults
}

\author{
Min-Sik Yong, PT, PhD ${ }^{1)}$, Hae-Yong Lee, PT, PhD ${ }^{1)}$, Yun-Seob Lee, PT, $\mathrm{PhD}^{1)^{*}}$ \\ 1) Department of Physical Therapy, Youngsan University: 288 Joonam-ro, Yangsan, \\ Gyeongsangnam-do, Republic of Korea
}

\begin{abstract}
Purpose] The present study investigated effects of diaphragm breathing exercise and feedback breathing exercise on respiratory function. [Subjects and Methods] Thirty-one subjects were randomly assigned to two groups; the feedback breathing exercise group and the maneuver-diaphragm exercise group. The feedback breathing exercise group was asked to breathe with feedback breathing device, and the maneuver-diaphragm exercise group was asked to perform diaphragm respiration. Respiratory function was evaluated when a subject sat on a chair comfortably. [Results] There was a significant difference in the functional vital capacity and slow vital capacity before and after all breathing exercises. There was a significant between-group difference in functional vital capacity. However, no between-group difference was found in slow vital capacity. [Conclusion] Diaphragm breathing exercise and feedback breathing exercise can affect respiratory function.

Key words: Diaphragm breathing exercise, Feedback breathing exercise, Respiratory function
\end{abstract}

(This article was submitted Aug. 1, 2016, and was accepted Oct. 5, 2016)

\section{INTRODUCTION}

Respiration indicates exchange of oxygen and carbon dioxide between the air and the tissues. It is controlled by activities of respiratory muscles and neurological mechanism ${ }^{1,2}$. The diaphragm, one of respiratory muscles, plays a key role in the respiratory pump. In addition, it influences respiratory function of controlling breathing as well as human posture ${ }^{3-5)}$. The respiration performed by diaphragmatic contraction is the diaphragmatic respiration ${ }^{6}$. There have been many studies related to it so far; the diaphragmatic respiration has been used in various fields including Pilates, yoga, and exercises emphasizing core stability ${ }^{7}$. In particular, the lung functions and the trunk stability can be promoted through the diaphragmatic respiration ${ }^{8)}$. It is expected that respiratory function is improved by increasing strength and endurance in respiratory muscles through various types of exercise ${ }^{9}$. Previous studies reported that respiratory exercise using feedback respiratory device has been usually used as a respiratory exercise method for recovering respiratory function. It was reported that endurance and quality of life in patients with chronic obstructive pulmonary disease were facilitated through feedback breathing device which can enhance both inspiration and expiration simultaneously ${ }^{10)}$. The intervention depends on the training using respiratory devices due to time restriction although applying direct respiratory training to patients who need respiratory therapy is needed. Respiration is one of the most important issues for life conservation, and its significance has been mentioned in many studies ${ }^{11)}$. In this regard, it is necessary to measure exact pulmonary function. The present study investigated effects of diaphragm breathing exercise and feedback breathing exercise on respiratory function.

\footnotetext{
*Corresponding author. Yun-Seob Lee (E-mail: leeys@ysu.ac.kr)

(C)2017 The Society of Physical Therapy Science. Published by IPEC Inc.

This is an open-access article distributed under the terms of the Creative Commons Attribution Non-Commercial No Derivatives (by-nc-nd) License $<$ http://creativecommons.org/licenses/by-nc-nd/4.0/>.
} 
Table 1. Effects of feedback breathing exercise and diaphragm breathing exercise on SVC and FVC (Unit: liter)

\begin{tabular}{ccccc}
\hline & \multicolumn{2}{c}{ FBE } & \multicolumn{2}{c}{ MDBE } \\
\cline { 2 - 5 } & pre & post & pre & Post \\
\hline SVC & $5.85 \pm 1.5$ & $6.44 \pm 1.3^{*}$ & $5.32 \pm 1.4$ & $6.05 \pm 1.3^{*}$ \\
FVC & $3.05 \pm 0.6$ & $3.30 \pm 0.6^{*}$ & $2.86 \pm 0.8$ & $3.27 \pm 0.7^{*} \#$ \\
\hline
\end{tabular}

Values are reported as the Mean $\pm \mathrm{SD}$.

$* \mathrm{p}<0.05$ vs. pre, $\# \mathrm{p}<0.05$ vs. FBE post

\section{SUBJECTS AND METHODS}

Thirty-one subjects with no history of neuromuscular, orthopedic, and cardiopulmonary disorder participated in this study. They were randomly assigned to two groups; the feedback breathing exercise (FBE) group ( $\mathrm{n}=15$; age, $20.79 \pm 0.85$ years; height, $160.22 \pm 8.53 \mathrm{~cm}$; weight, $59.17 \pm 9.66 \mathrm{~kg}$ ) and the maneuver-diaphragm exercise (MDE) group ( $\mathrm{n}=16$; age, 21.8 \pm 1.61 years; height, $167.87 \pm 8.03 \mathrm{~cm}$; weight, $62.73 \pm 9.38 \mathrm{~kg}$ ). The purpose and procedures of this study were explained to all subjects, and they provided written informed consent prior to participation. This study adhered to the Declaration of Helsinki. FBE group was asked to sit with a mouthpiece in his/her mouth, watching the TIGER ${ }^{\circledR}$ mainframe. The investigator pressed the start button, and the subject breathed in when the orange needle directed toward the "In" mark and breathed out when the needle toward the "OUT." Before the exercise, the investigator taught the subjects how to accurately perform the exercise two or three times for them to adjust to the method. MBE group was asked to put his/her hands on the rectus abdominis muscle immediately below the anterior costal cartilage, and to inhale slowly and deeply only by swelling his/her abdomen without moving his/her upper chest while relaxing his/her shoulders. Then, the subject exhaled all the air slowly. During inhalation, the air was breathed in through his/her nose, and his/her abdomen was swollen. After the breathe was suspended at the last moment, the subject exhaled the air according to the pursed lip breathing, with which the subject breathed out the air through his/her mouth with his/her lips half-opened and his/her abdomen made hollow. CardioTouch 3000S (BIONET, Korea) was used to evaluate respiratory function when a subject sat on a chair comfortably. All subjects were given sufficient explanation and demonstration for enhancing accuracy before measuring. Paired t-test and independent t-test were used to examine effects of feedback breathing and diaphragm breathing on respiratory function. Statistical analyses were performed using SPSS ver. 21.0, and statistical significance was set at $\mathrm{p}<0.05$.

\section{RESULTS}

There was a significant difference in the functional vital capacity (FVC) and slow vital capacity (SVC) before and after all breathing exercises $(\mathrm{p}<0.05)$. There was a significant between-group difference in $\mathrm{FVC}(\mathrm{p}<0.05)$. However, no betweengroup difference was found in SVC ( $>>0.05)$ (Table 1).

\section{DISCUSSION}

Respiration, the process in which oxygen in the air is sent to the tissues and carbon dioxide is emitted to the air, can be divided into thoracic and diaphragmatic respiration basically ${ }^{12,13}$. In particular, there have been many researches using diaphragmatic respiration. The concept of the diaphragmatic respiration is applied to strengthening exercise for abdominal and back muscles, and the exercise is introduced as a therapeutic approach for musculoskeletal disorders ${ }^{14)}$. The diaphragm chiefly used in the diaphragmatic respiration has significant influence on back pain ${ }^{3)}$. In addition, it may prevent falling through maintaining the center of gravity $(\mathrm{COG})$ within the base of support $(\mathrm{BOS})^{15}$. The present study compared diaphragm breathing exercise and feedback breathing exercise in order to investigate which method may affect respiratory function more significant. From the results obtained, significant differences in FVC and SVC were observed before and after all breathing exercises $(p<0.05)$. Significant between-group difference in FVC was observed $(p<0.05)$ although no significant difference in SVC was observed $(\mathrm{p}>0.05)$. In the breathing exercise using the feedback respiratory device, the subjects used the breathing accessory muscles more than the diaphragm, showing thoracic respiration by raising their shoulders or moving their chests for excessive inhalation and exhalation. Such result is consistent with that of the study in which breathing exercise using threshold device did not induce changes in diaphragmatic activities but significantly increase activities of the sternocleidomastoid muscle ${ }^{16}$. The MDBE group showed exhalation resistance with their lips pursed accompanied with diaphragmatic respiration; the group showed higher increase in FVC maybe because they used the diaphragm more than the FBE group. It is suggested that the results of the present study can be used as the baseline data for development of new type of breathing exercise. 


\section{ACKNOWLEDGEMENT}

This research was supported by Youngsan University Research Grants in 2016.

\section{REFERENCES}

1) Pryor JA, Prasad AS: Physiotherapy for respiratory and cardiac problems: adults and paediatrics. Elsevier Health Sciences, 2008.

2) Sherwood L: Human physiology: from cells to systems. Cengage learning, 2015.

3) Kalpakcioglu B, Altinbilek T, Senel K: Determination of spondylolisthesis in low back pain by clinical evaluation. J Back Musculoskeletal Rehabil, 2009, 22: 27-32. [Medline] [CrossRef]

4) Hodges PW, Sapsford R, Pengel LH: Postural and respiratory functions of the pelvic floor muscles. Neurourol Urodyn, 2007, 26: 362-371. [Medline] [CrossRef]

5) Kim E, Lee H: The effects of deep abdominal muscle strengthening exercises on respiratory function and lumbar stability. J Phys Ther Sci, 2013 , 25 : 663-665. [Medline] [CrossRef]

6) Janke J: The effect of relaxation therapy on preterm labor outcomes. J Obstet Gynecol Neonatal Nurs, 1999, 28: 255-263. [Medline] [CrossRef]

7) Muscolino JE, Cipriani S: Pilates and the "powerhouse"-I. J Bodyw Mov Ther, 2004, 8: 15-24. [CrossRef]

8) Kolar P, Sulc J, Kyncl M, et al.: Stabilizing function of the diaphragm: dynamic MRI and synchronized spirometric assessment. J Appl Physiol 1985, 2010, 109: 1064-1071. [Medline] [CrossRef]

9) Carr M, Jones J: Physiological effects of exercise on stroke survivors. Top Stroke Rehabil, 2003, 9: 57-64. [Medline] [CrossRef]

10) Koppers RJ, Vos PJ, Boot CR, et al.: Exercise performance improves in patients with COPD due to respiratory muscle endurance training. Chest, 2006, 129: 886-892. [Medline] [CrossRef]

11) Skinner JS: Exercise testing and exercise prescription for special cases: theoretical basis and clinical application. Lippincott Williams \& Wilkins, 2005.

12) Gardner WN: The pathophysiology of hyperventilation disorders. Chest, 1996, 109: 516-534. [Medline] [CrossRef]

13) Fried R: The psychology and physiology of breathing. In: behavioral medicine, clinical psychology, and psychiatry. Springer Science \& Business Media, 1993.

14) Mehling WE: The experience of breath as a therapeutic intervention—psychosomatic forms of breath therapy. A descriptive study about the actual situation of breath therapy in Germany, its relation to medicine, and its application in patients with back pain. Forsch Komplementarmed Klass Naturheilkd, 2001, 8: 359-367. [Medline] [CrossRef]

15) Nordin M, Frankel VH: Basic biomechanics of the musculoskeletal system, Lippincott Williams \& Wilkins, 2001.

16) de Andrade AD, Silva TN, Vasconcelos H, et al.: Inspiratory muscular activation during threshold therapy in elderly healthy and patients with COPD. J Electromyogr Kinesiol, 2005, 15: 631-639. [Medline] [CrossRef] 